\title{
EFEITO DAS ADIÇÕES MINERAIS NA REDUÇÃO DA FISSURAÇÃO DE CONCRETO EM BARRAGENS: REVISÃ O DE LITERATURA
}

\author{
CRUZ DA SILVA ARAUJO, JULIENE \\ Graduanda \\ UFPA \\ Pará; Brasil \\ julliene.silva@hotmail.com
}

\author{
PEREIRA BONFIM, FRANCIRENE \\ Técnica do Laboratório \\ UFPA \\ francy_pb@hotmail.com
}

\author{
PEREIRA GOUVEIA, FERNANDA \\ Docente, Dr ${ }^{\mathrm{a}}$. \\ UFPA \\ Pará; Brasil \\ gouveia@ufpa.br
}

\section{RESUMO}

A construção de barragens de concreto requer a utilização de grandes volumes de cimento e consequentemente aumento do calor de hidratação na fase de mistura, proporcionando muitas vezes, patologias tais como fissuras de origem térmica. Neste sentido, algumas das técnicas utilizadas para minimizar este efeito é utilização de adições minerais em substituição ao cimento. Logo, a presente pesquisa teve como objetivo identificar e discutir quais as adições mais utilizadas na redução do calor de hidratação em concreto massa, em especial em barragens, sendo este problema um dos mais recorrentes em empreendimentos desta tipologia. A metodologia do trabalho foi baseada em revisão da literatura técnico - científica, demonstrando que as adições mais utilizadas em barragens são cinza volante, sílica ativa e metacaulim, sendo identificado os teores usados nos traços de barragens brasileiras. O uso destes materiais são fundamentais para a redução significativa do calor de hidratação do cimento, e consequentemente no combate à fissuras, aumentando a segurança estrutural das estruturas de concreto massa.

Palavras-chave: calor de hidratação, fissuras térmicas, barragem de concreto, adição mineral.

\section{ABSTRACT}

The construction of concrete dams requires the use of large volumes of cement and consequently increased hydration heat in the mixing phase, often providing pathologies such as thermal cracks. In this sense, some of the techniques used to minimize this effect is the use of mineral additions to replace cement. Therefore, this research aimed to identify and discuss which are the most used additions in the reduction of hydration heat in concrete mass, especially in dams, and this problem is one of the most recurrent in projects of this type. The research methodology was based on a review of the technical - scientific literature, showing that the most used additions in dams are fly ash, active silica and metakaolin, and the levels used in the traces of Brazilian dams were identified. The use of these materials is fundamental to significantly reduce the heat of cement hydration, and consequently to fight against cracks, increasing the structural safety of big concrete structures.

Keywords: hydration heat, thermal cracking, concrete dam, mineral addition.

\section{INTRODUÇÃO}

Nas concretagem em estruturas de grande porte como empreendimentos de barragens, são utilizados grandes volumes de concreto, chamado de concreto-massa. Conforme American Concrete Institute (ACI, 2005) o concreto massivo é qualquer volume de concreto com dimensões grandes o suficiente para exigir que sejam tomadas medidas para controlar o calor de hidratação do cimento. Nesse tipo de concreto devem-se tomar precauções para que sejam evitadas fissuras por retração térmica decorrentes do calor de hidratação.

De acordo com Metha e Monteiro (2008) várias são as causas das fissuras em barragens: reação álcali-agregado, corrosão da armadura, ataque de sulfatos, retração plástica, assentamento do concreto, erros de acabamento, 
congelamento e degelo, concretagem em rampa, movimento das formas, assentamento das fundações, fissuras por carregamentos excessivos, etringita tardia e as alterações volumétricas geradas pelo calor de hidratação no concreto.

Ainda, de acordo com Couto, Helene e Almeida (2016), um dos principais problemas no uso do concreto massa é o controle de fissuração de origem térmica, decorrentes de reações exotérmicas do cimento ao entrar em contato com a água libera alto calor de hidratação. Nas grandes estruturas isso ocorre devido o alto consumo de cimento, resultando em uma taxa de geração de calor maior do que a taxa de dissipação para o meio ambiente, no qual há o armazenamento de calor no interior dessas estruturas.

Vale ressaltar que a abertura das fissuras compromete a segurança estrutural dos empreedimentos, principalmente, as barragens, que são projetadas para suportarem elevadas tensões hidrostáticas. A presença das físsuras além de permitirem a entrada de agentes agressivos que ocasionam deteriorações no concreto, permitem a infiltração de água no interior do concreto, carreando os materiais constituintes, e consequentemente aumentando a abertura das mesmas, o que pode levar ao colapso estrutural. De acordo com Metha e Monteiro (2008) uma estrutura livre de fissuras mantém a segurança estrutural da fundação com os apoios laterais e se comporta de acordo com o previsto no projeto. Logo, essa pesquisa tem por objetivo realizar um levantamento bibliográfico das adições minerais que influenciam no calor de hidratação do concreto-massa que atuam diretamente no combate à fissuração desses elementos estruturais.

\section{METODOLOGIA}

A metodologia da pesquisa foi baseada em revisão da literatura técnico-científica relacionada a uma abordagem sobre as adições minerais mais utilizadas em concreto massa, visando o controle do calor de hidratação do cimento no processo de produção do concreto, sendo dado enfoque sobre a influência destas adições quanto à prevenção de patologias do tipo fissuras de origem térmica.

O período em que ocorreu a pesquisa científica foi entre os meses de agosto de 2019 a novembro 2019, onde foram utilizadas as bases de consulta de dados do Periódico Capes (artigos), bibliotecas online de Universidades (dissertações e teses) e Relatórios Técnicos De Dosagem de barragens brasileiras. As palavras chaves que ajudaram a localizar os trabalhos foram: Calor de hidratação, adições minerais, concreto massa, sílica ativa, cinza volante, metacaulin escória de alto-forno, entre outros. Ao final da pesquisa foram consultados quarenta e um trabalhos, sendo vinte e sete na língua portuguesa e quatorze em língua inglesa.

\section{RESULTADOS E DISCUSSÕES}

\subsection{Calor de Hidratação}

Taylor (1997) analisou o calor de hidratação do cimento identificando no gráfico "tempo versus taxa de calor gerado" os seguintes períodos: pico de reação inicial, período de indução, período acelerado, período desacelerado e um período de reação lenta contínua. No período acelerado, os silicatos começam a se hidratar rapidamente atingindo uma taxa máxima. O final do período de aceleração corresponde à taxa máxima de evolução do calor. Durante o período desacelerado, a reação faz uma transição do controle da reação química para o controle difusional. Essa curva (Figura 1) é fundamental para o entendimento do comportamento da evolução do calor de hidratação dos cimentos, sendo determinada a partir do ensaio em calorímetro adiabático (explicitado a seguir).

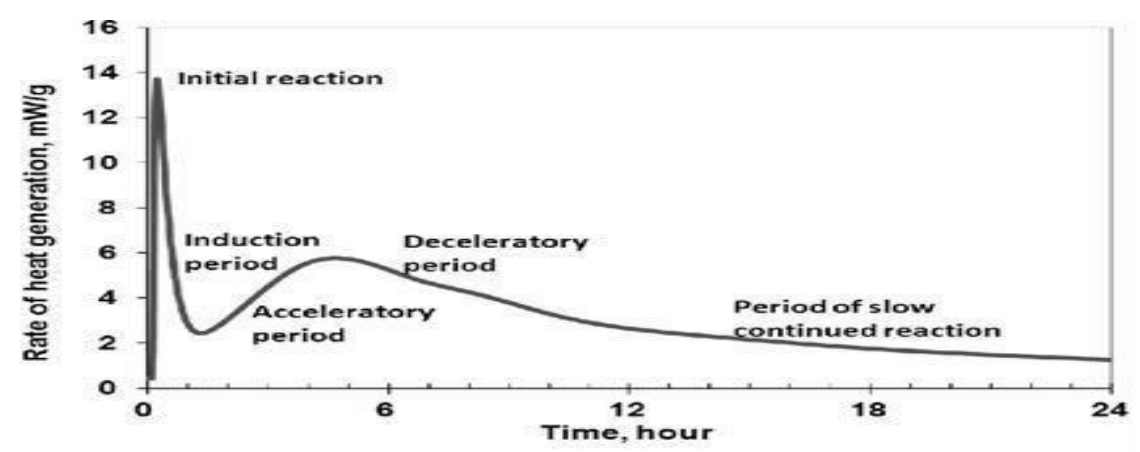

Figura 1: Curva de calor de hidrataçãoem cimento. Fonte: Taylor (1997). 
Neville (2016) explica que os principais compostos hidratados do cimento são classificados como silicatos de cálcio hidratados e aluminato tricálcico hidratado $\left(\mathrm{C}_{3} \mathrm{~S}\right.$ e $\left.\mathrm{C}_{3} \mathrm{~A}\right)$, no qual a velocidade de hidratação do cimento é afetada pela interação entre eles. Portanto, para redução do calor de hidratação nas primeiras idades do concreto é necessário reduzir a proporção desses compostos que são responsáveis pela maior velocidade de hidratação do cimento.

O mesmo autor verificou que existem três picos de velocidade de hidratação nos três primeiros dias, que acontecem desde o momento em que o cimento entra em contanto com a água. O primeiro pico é bastante elevado devido à hidratação inicial dos grãos de cimento e as reações, principalmente do $\mathrm{C}_{3} \mathrm{~A}$, porém tem duração curta. Após este pico ocorre o período de dormência ou de indução, no qual a velocidade de hidratação é bastante baixa. Com crescimento dos cristais de hidróxido de cálcio há a ruptura da camada superficial e um aumento lento na liberação do calor que proporciona a ocorrência do processo de pega alcançando o segundo pico de liberação de calor, após cerca de 10 horas. Após este pico a velocidade hidratação diminui por um longo período de tempo. Já no terceiro pico há um aumento na velocidade de hidratação que ocorre com a retomada nas reações do C3A devido ao esgotamento do sulfato de cálcio.

Entre as medidas para controlar o aumento de temperatura no interior do concreto conforme Furnas (1997) estão: técnicas de pré-resfriamento, redução do consumo de cimento, a utilização de cimento com baixo calor de hidratação, utilização de adições minerais como as pozolanas, entre outros. Neville (2016) complementa que a quantidade cimento influencia no calor de hidratação e para minimizá-lo é necessário controlar o teor de cimento na mistura. A substituição parcial da quantidade de cimento por adições pozolânicas é uma forma de reduzir o consumo do cimento, e consequentemente, reduzir o calor de hidratação.

Esse calor produzido nas reações exotérmicas do cimento em concretos é determinado através do ensaio de elevação adiabática conforme a ABNT NBR 12819:2012, no qual consistem em um calorímetro constítuído de duas câmaras uma interna e outra externa dotada de um sistema de aquecimento e resfriamento, simulando uma estrutura real de concreto massa. Nesse ensaio é gerada uma curva de elevação adiabática da temperatura do concreto, no qual é possível analisar de acordo com o tempo a temperatura atingida pelo concreto. Além disso, existem softwares de simulação que são utilizados para estimar a temperatura no interior do concreto e estudos numéricos baseados em Método dos Elementos Finitos. Porém, apesar desses métodos resultarem em uma boa aproximação, apenas o ensaio de elevação adiabática simula as condições reais de uma grande massa de concreto.

O ensaio para determinação do calor de hidratação em Cimento Portland é realizado através de dois métodos, sendo estes, método isotérmico de indução e método semi-adiabático. O primeiro utiliza um equipamento chamado de Tam Air, no qual, segundo Júnior (2018) determina as velocidades de reação e o grau de hidratação para as temperaturas definidas no ensaio, pois nesse procedimento a temperatura de ensaio é constante. Ressalta-se que este método é normalizado pela ASTM 1702:2017, não sendo ainda normalizado no Brasil. O método com calorímetro semiadiabático (Método da Garrafa de Langavant), consiste em uma garrafa que possui uma ampola de vidro de parede dupla, espelhada e com forte vácuo entre as paredes, fechada com uma tampa isolante (ABNT NBR 12006:1990). Nessa garrafa é introduzida um recipiente cilindro metálico contendo argamassa de cimento e através de um termômetro ou termopar é realizada a medição da temperatura em intervalos pré-definidos por um período de 7 dias. A Figura 2 apresenta o calorímetro adiabático do concreto e a Figura 3 o calorímetro semi-adiabático "Garrafa de Langavant".

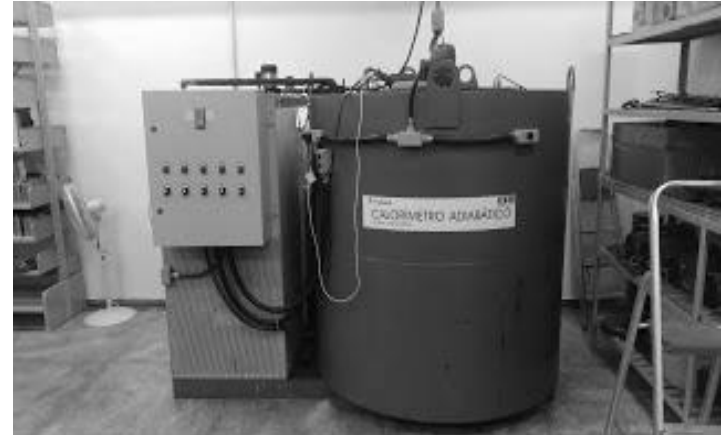

Figura 2: Calorímetro adiabático de concreto. Fonte: Júnior (2018).

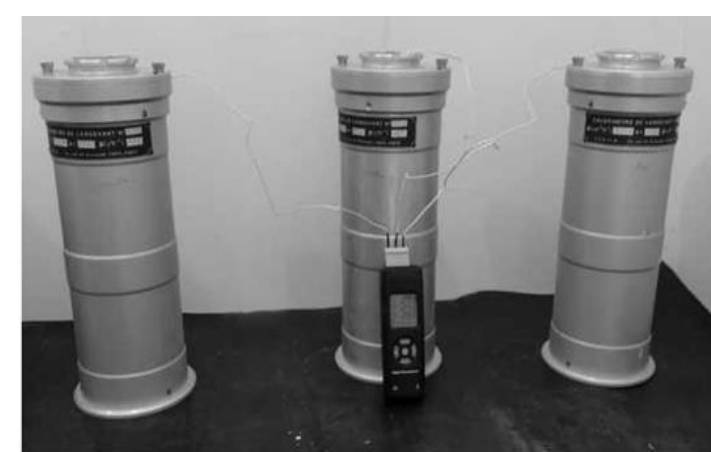

Figura 3: "Garrafa de Langavant". Fonte: dos autores. 


\subsection{Adições Minerais}

Adição mineral é um material fino, derivado de algum processo industrial que são adicionadas ao cimento ou substituídas por parte dele com o objetivo de melhorar as propriedades da mistura no estado fresco ou endurecido. As propriedades desses materiais variam de acordo o processo de produção, sendo que para aplicações no concreto massa buscam-se adições com propriedades pozolânicas, que possam reduzir o consumo de cimento na mistura, e consequentemente redução do custo e melhoria das propriedades do concreto.

De forma geral, as adições mais utilizadas em substituição ao cimento, na produção de concretos massa, são as adições pozolânicas, tais como a sílica ativa, cinza volante, metacaulim, etc., que geram matrizes mais duráveis, devido à reação pozolânica, que consome o hidróxido de cálcio e produz compostos de silicatos e aluminatos de cálcio hidratados (SILVA, 2016). Em outras palavras, a atividade pozolânica é a aptidão que certos materiais possuem para, na presença de água, fixarem o hidróxido de cálcio formando hidratos com propriedades cimentícias (BICH, 2005). A Equação 1 explicita a reação pozolânica, a saber:

$$
3 \mathrm{Ca}(\mathrm{OH})_{2}+\mathrm{SiO}_{2} \rightarrow 3 \mathrm{CaO} . \mathrm{SiO}_{2}+3 \mathrm{H}_{2} \mathrm{O}
$$

Hidróxido de cálcio + sílica $\rightarrow$ silicato tricálcico + água

Podem-se citar também as adições cimentantes, a exemplo da escória de alto forno, que de acordo com Santos (2011) são adições que, independente do cimento, forma em contato com a água produtos cimentantes, como o C-S-H de menor densidade e de forma mais lenta.

Logo, a utilização de adições minerais tem a finalidade principal de reduzir o consumo de cimento associado aos aspectos térmicos e econômicos, auxiliando na minimização do calor de hidratação do cimento e consequente redução do surgimento de fissuras no concreto. A seguir serão apresentadas, em detalhes, as adições mais utilizadas em concreto massa.

\subsubsection{Sílica Ativa}

A sílica ativa é um material fino resultante do processo industrial da produção do ferrosílicio ou sílicio metálico. De acordo com a ABNT NBR 13956-1: 2012, a sílica ativa é classificada como um mateiral pozolânico formado por partículas esféricas com diâmetros menores que $10^{\wedge}-6 \mathrm{~m}$ de sílica no estado amorfo. No processo de produção do sílicio metálico é gerado o gás $\mathrm{SiO}$ e ao sair do forno transforma-se em particulas de $\mathrm{SiO} 2$ que são captadas por filtros coletores, esse material fino captado é a sílica ativa, também chamada de fumo de sílica ou microssílica

Vários autores observaram redução significativa do calor de hidratação em misturas com adição de sílica ativa. Bianchini (2010), em seus estudos observou que quanto maior o teor de sílica ativa menor é o calor de hidratação gerado. Ao utilizar teores de sílica de 3\%,6\%,9\% e 12\% de substituição em relação à massa do cimento, a amostra contendo $12 \%$ de sílica ativa foi a que apresentou menor calor de hidratação. Isso se justifica devido quanto maior o teor de sílica adicionada, menor a quantidade de cimento, e consequentemente menor calor de hidratação.

Kawan et al. (2011), analisaram o calor de hidratação em concreto de alto desempenho com adição de sílica ativa, cinza volante e uma mistura com as duas adições em conjunto. De acordo com o autor a substituição do cimento por sílica ativa foi mais eficaz na redução do calor de hidratação do que a cinza volante, pois as misturas com sílica ativa nos teores de $5 \%$ e $10 \%$ reduziram a quantidade de calor em aproximadamente $10 \%$ e $20 \%$, respectivamente. Resultados satisfatórios também foram observados nos estudos de Singh et al. (2015) em uma mistura com a utlização da adição de $20 \%$ de cinza volante e outra com $20 \%$ de cinza volante juntamente com $5 \%$ de sílica ativa em substituição ao cimento, os autores verificaram que essas adições retardaram a hidratação do cimento e reduziram o calor de hidratação.

Portanto, constata-se a existência do potencial da sílica ativa quando incorporada ao concreto, pois além da função na redução do calor de hidratação, que é um dos responsáveis pelas patologias de origem térmicas que surgem nos concretos; ela também contribui no ganho de resistências e no combate às reações álcali-agregado.

\subsubsection{Cinza Volante}

De acordo com a ABNT NBR 12653:2015 a cinza volante é um material fino proveniente das usinas termoelétricas a partir da queima do carvão mineral. A composição básica desse material é o silício e o alumínio, porém, a sua 
composição mineralógica depende do processo de produção, ou seja, do tipo do carvão utilizado na queima e o tipo de queima.

Rong et al. (2014) estudaram cinza volante adicionada aos compósitos cimenticios e constataram retardo na hidratação do cimento em relação ao cimento sem adição, principalmente nos períodos de latência e aceleração, retardando ainda o pico de calor da mistura. Estudos realizados por Kim, Yang e Moon (2015) analisaram as características de hidratação do cimento com substituição de $20 \%$ de cinza volante, resultando no retardo do período de indução na curva de calor de hidratação e aumento do valor máximo do fluxo de calor em comparação com cimento de referência (sem adição); à medida que a proporção e a finura da cinza volante aumentavam, o período de indução da curva de calor de hidratação era prolongado e o valor máximo do fluxo de calor aumentava.

Resultados sastifatórios támbem foram observados por Singh et al. (2015), seus estudos determinaram que a adição de $20 \%$ de cinza volante em substituição ao cimento retarda a hidratação do cimento e reduz o calor de hidratação. Também foi realizada uma mistura com $20 \%$ de cinza volante juntamente com $5 \%$ de sílica ativa e o calor de hidratação aumentou um pouco, porém menor que o concreto de referência.

Wang e Yan (2006), estudaram a influência da temperatura de fundição e da dosagem na evolução do calor de hidratação em concretos sob condição adiabática, com substituição em relação a massa do cimento de $20 \%$ da cinza volante, $20 \%$ de escória de alto forno e $10 \%$ de sílica ativa. Dentre os resultados, destaca-se que para o concreto sem adição a elevação da tempratura inicial acelera a taxa de hidratação do cimento, e baixa temperatura inicial diminui a taxa de hidratação do cimento, porém prolonga o tempo de hidratação e aumenta o grau de hidratação. Para o concreto de $80 \%$ de cimento Portland e $20 \%$ de cinza volante sob alta temperatura inicial, a taxa de emissão de calor de hidratação foi menor e a reação de hidratação maior quando comparado ao concreto sem adição.

A relação a/c támbem é um dos fatores que influencia na quantidade de calor gerado. Isso foi observado nos estudos de Langan, Weng e Ward (2002), a sílica ativa acelera a hidratação do cimento em altas relações a/c e retarda a hidratação em baixa relação a/c. Já a cinza volante retarda a hidratação de forma mais significativa em altas relações a/c. Ainda segundo os autores, para os teores de $20 \%$ cinza volante e de $10 \%$ sílica ativa incorporadas juntas no cimento Portland a hidratação do cimento foi significativamente retardada.

Matos, Junckes e Prudêncio (2019) evidenciam que a cinza contribui no aumento da resistência do concreto e atua para evitar a formação da etringita tardia, a qual ocorre quando o armazenamento do calor no interior da estrutura atinge níveis muito altos, ocasionando segundo Melo (2010), problemas patológicos no concreto, como fissuras, expansão e deterioração do material. Além disso, Han et al. (2014), destaca que ao comparar as mesmas quantidades de substituição de cinzas volantes e escória em compostos cimenticios, a emissão de calor do cimento com cinzas volantes é menor.

A quantidade de aglomerante presente na mistura influencia diretamente no calor de hidratação, isso foi observado nos estudos de Graeff (2017) ao estudar consumos de aglomerantes nos teores de $200 \mathrm{~kg} / \mathrm{m}^{3}, 250 \mathrm{~kg} / \mathrm{m}^{3}$ e $300 \mathrm{~kg} / \mathrm{m}^{3} \mathrm{com}$ teores de susbtituição de cinza volante de $0 \%, 15$ e $30 \%$. Foi utilizado um valor extra de substituição de $45 \%$ para o consumo de aglomerante de $200 \mathrm{~kg} / \mathrm{m}^{3}$. Através do ensaio de elevação adiabática os resultados mostraram que a substituição de cimento por cinza volante apresentou redução na elevação adiabática de temperatura à medida que o teor de cinza aumentava. Porém, apenas para a mistura com teor de aglomerante de $300 \mathrm{~kg} / \mathrm{m}^{3}$ e com $15 \%$ de cinza volante que apresentou uma redução apenas de $2 \%$.

\subsubsection{Metacaulim}

Conforme citado por Medina (2011), o metacaulim é um material amorfo, constiutido basicamente de sílica $\left(\mathrm{SiO}_{2}\right)$ e alumina $\left(\mathrm{Al}_{2} \mathrm{O}_{3}\right)$, obtido pelo processo industrial de ativação térmica entre $600^{\circ} \mathrm{C} \mathrm{e} 850^{\circ} \mathrm{C}$ seguido do processo moagem de argilas cauliníticas e caulins. De acordo a ABNT NBR 12653:2014, esse material se classifica como uma pozolana artifical, pois é um subproduto industrial provenientes de tratamento térmico.

Ribeiro (2018) a partir dos ensaios de calorimetria adiabática observou que a substituição do cimento por $12 \%$ de metacaulim em concreto massa apresentou menor liberação de calor quando comparado à concretos apenas com cimento. Além disso, o autor afirma que um volume de substituição de $12 \%$ de metacaulim inibe a formação a formação da etringita tardia, diminuindo também o problema com a fissuração térmica, pois se observou que o ganhode 
temperatura para cada Mpa foi menor para o concreto com adição do que o concreto produzido apenas com cimento CP V- ARI.

Jiang, Rong e Sun (2015) ao avaliarem a substituição do cimento por metacaulim nos teores de $0 \%, 6 \%, 10 \%$ e $14 \%$. Os resultados dos testes de calor de hidratação mostraram que as misturas contendo com $10 \%$ e $14 \%$ de metacaulim apresentaram minimização significativa no calor total desenvolvido. Porém, o autor afirma o teor ideal de metacaulim é de $10 \%$, pois apresentou melhores propriedades mecânicas.

Resultados sastifatórios também foram observados por Saad et al. (1982) apud Souza (2003) com a utilização do metacaulim com superficie específica de $850 \mathrm{~m}^{2} / \mathrm{kg}$ em concreto massa nos teores de adotados de $30 \%$ e $50 \%$, obtendo com resultados a diminuição do calor de hidratação, principalmente nas idades iniciais.

$\mathrm{Na}$ construção de barragens tem-se a preocupação com relação ao calor de hidratação gerado no processo de concretagem, sendo uma das soluções adotadas a utilização de adições minerais em substituição ao cimento. Desta forma, tem-se a Tabela 1 contendo um resumo sobre as adições minerais mais utilizadas em concretos dosados para este fim.

Tabela 1 - Adições Minerais Utilizadas em Barragens brasileiras. Fonte: dos autores.

\begin{tabular}{|c|c|c|c|}
\hline Barragem & Adição Mineral & Teor $(\%)$ & Fonte \\
\hline UHE - Corumbá I (GO) & Sílica Ativa & 11 & $\begin{array}{l}\text { Hasparyk, Cavalcante e } \\
\text { Andrade (2006) }\end{array}$ \\
\hline UHE - Cana Brava (GO) & Sílica Ativa & 8 & $\begin{array}{l}\text { Haspary Cavalcante e } \\
\text { Andrade (2006) }\end{array}$ \\
\hline $\begin{array}{l}\text { UHE - São Salvador } \\
\text { (TO) }\end{array}$ & $\begin{array}{l}\text { Sílica Ativa } \\
\text { Metacaulim }\end{array}$ & $\begin{array}{l}8 \\
12\end{array}$ & FURNAS (2006) \\
\hline UHE-Itaipu Binacional & Cinza volante & $\begin{array}{l}\text { Não } \\
\text { identificado }\end{array}$ & Pedroso (2011) \\
\hline UHE - Jirau (RO) & $\begin{array}{l}\text { Argila Caulinítica } \\
\text { calcinada }\end{array}$ & 33 a 35 & Zannoti (2011) \\
\hline $\begin{array}{l}\text { UHE - Santo Antônio } \\
(\mathrm{RO}) \text {, }\end{array}$ & Sílica Ativa & $\begin{array}{l}\text { Não } \\
\text { identificado }\end{array}$ & $\begin{array}{l}\text { Guimarães, Nascimento e } \\
\text { Barbin (2011) }\end{array}$ \\
\hline UHE-Tucuruí (PA) & Pozolana & 21 & Lima e Nogueira (2016) \\
\hline UHE-Belo Monte (PA) & $\begin{array}{l}\text { Sílica ativa } \\
\text { Cinza volante }\end{array}$ & $\begin{array}{l}8 \text { a } 10 \\
25 \text { a } 35\end{array}$ & $\begin{array}{l}\text { Bandeira, Andrade e } \\
\text { Bittencourt (2017) }\end{array}$ \\
\hline UHE - Teles Pires (MT) & Metacaulim & 7 & Rocha apud Souza (2017) \\
\hline UHE - Pinalito & Metacaulim & 7,5 & Rocha apud Souza (2017) \\
\hline
\end{tabular}

\subsection{Fissuração em elementos de concreto massa}

Nas estruturas de concreto massa como as barragens, blocos de fundações, requerem cuidados especiais no processo de execução, principalmente na concretagem, com a utilização de dosagens de concreto que garantam a qualidade e segurança desses empreendimentos, como a minimização do calor de hidratação no interior das estruturas após a concretagem. O aumento da temperatura é uma consequência direta da evolução do calor de hidratação do cimento e as tensões de tração oriundas da queda de temperatura, podem resultar em fissuras no elemento de concreto. (JÚNIOR, 2018).

Casos de fissuração foram identificados na UHE Governador José Richa (GJR) nos blocos B-5 e B-8 (após o enchimento do reservatório e B-11(dois meses após o término do lançamento de concreto). De acordo com Soares et al. (2006) apud Godke (2014), as fissuras identificadas nos blocos são de origem térmica, resultantes das tensões internas da massa de concreto da barragem.

Ainda segundo o autor, essa ocorrência é devido o elevado consumo de cimento na concretagem desses elementos estruturais, o que se justifica que pelo maior consumo de cimento, maior é o calor gerado e maior a tensão no interior do concreto, provocando a formação de fissuras. Além disso, COPEL (2013) apud Godke (2014) cita que na concretagem desses elementos teve-se um aumento no ritmo da execução dos serviços devido o adiantamento do ínicio da geração de energia, e com isso devido à temperatura interna desses elementos chegaram a $47^{\circ} \mathrm{C}$, provocando as tensões de origem térmica no interior da estrutura. A Figura 4 apresenta a localização das fissuras na barragem. 


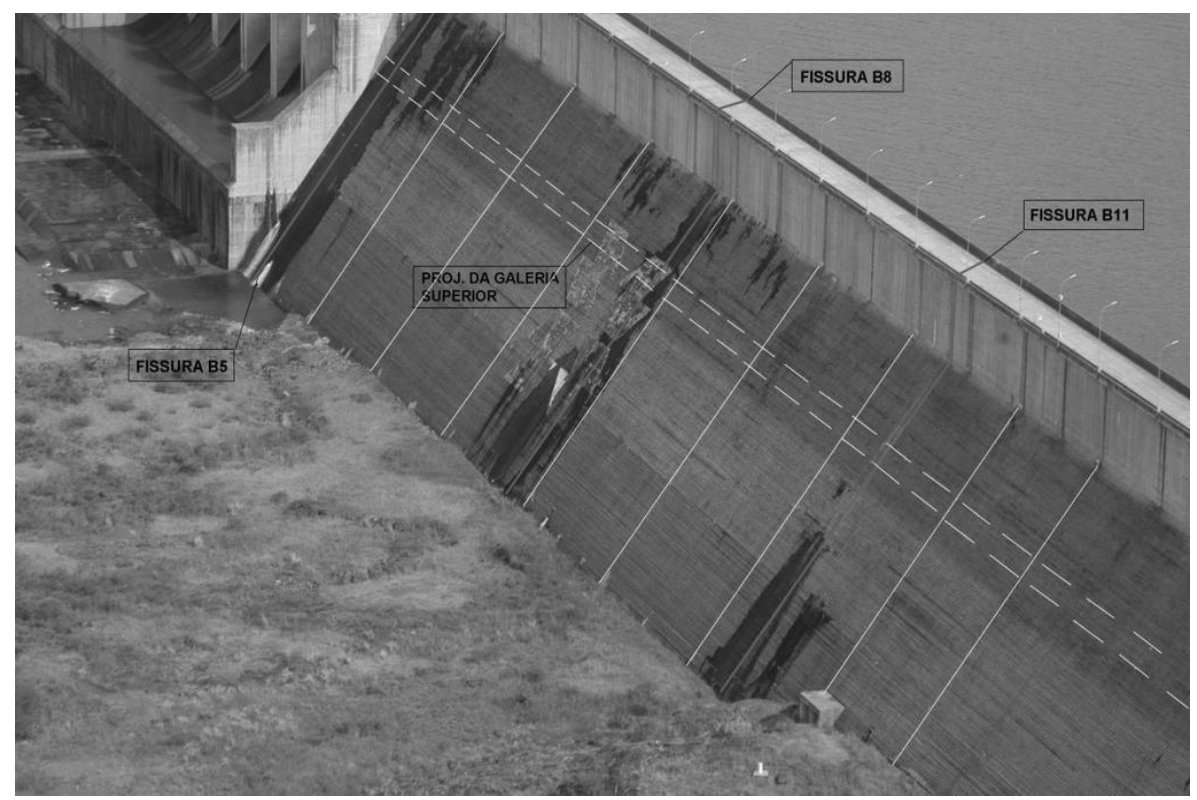

Figura 4. Localização das fissuras no Bloco B5, B8 e B11 na UHE GJR.

Fonte: Zorzi e Rigoti (2011).

Silveira, Ayres e Mantese (2018) apresentaram ocorrências de fissuras em contrafortes de uma barragem de concreto, destacando que este perfil trata-se de um comportamento típico de fissuras de origem térmica junto à fundação em contrafortes de barragens (Figura 5); apresenta ainda, um esquema de fissuras sub-verticais junto ao vértice da galeria de passagem que atravessa os contrafortes na parte central (Figura 6).

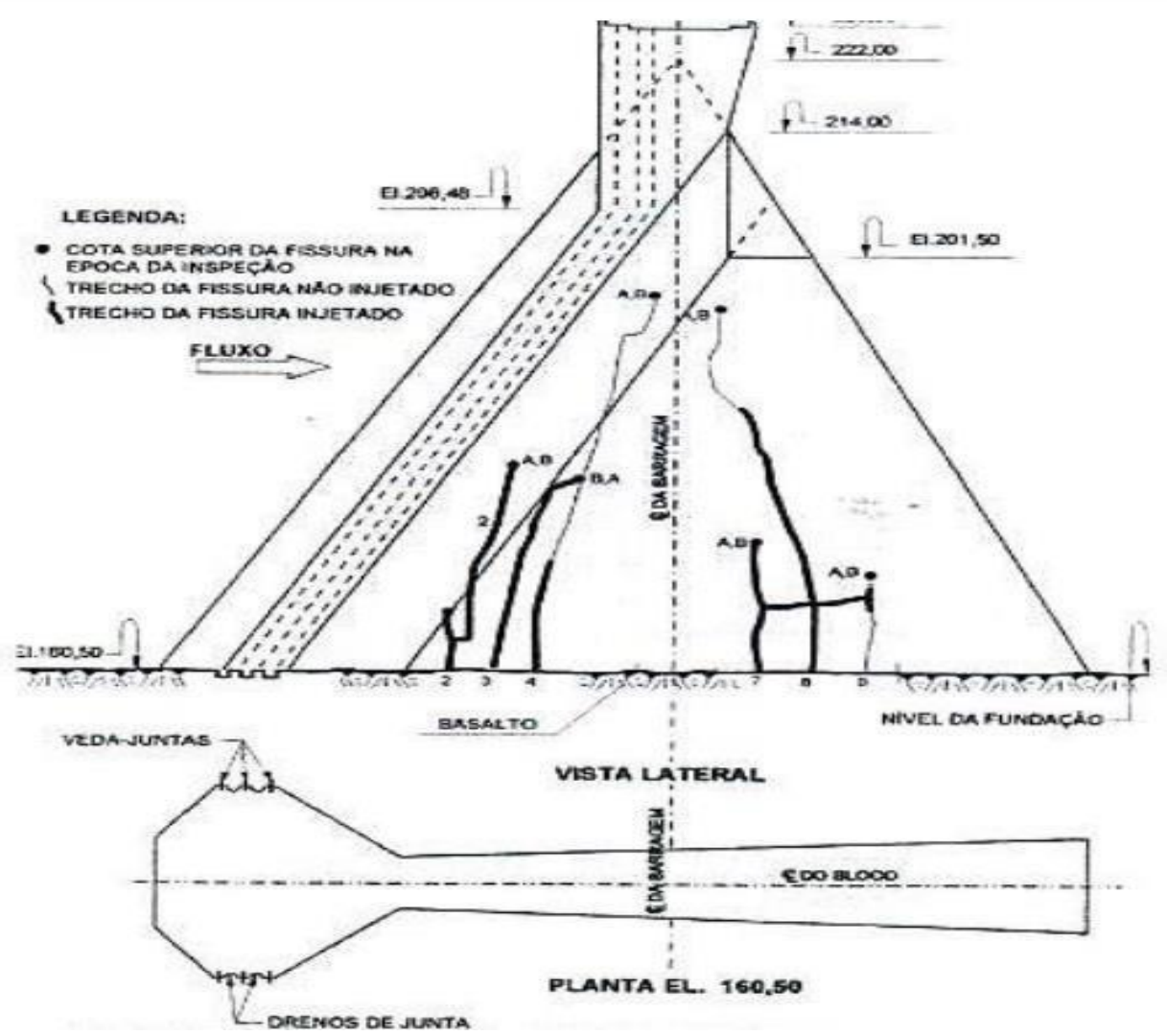

Figura 5. Fissuras de origem térmica em contrafortes de uma barragem.

Fonte: Silveira, Ayres e Mantese (2011). 


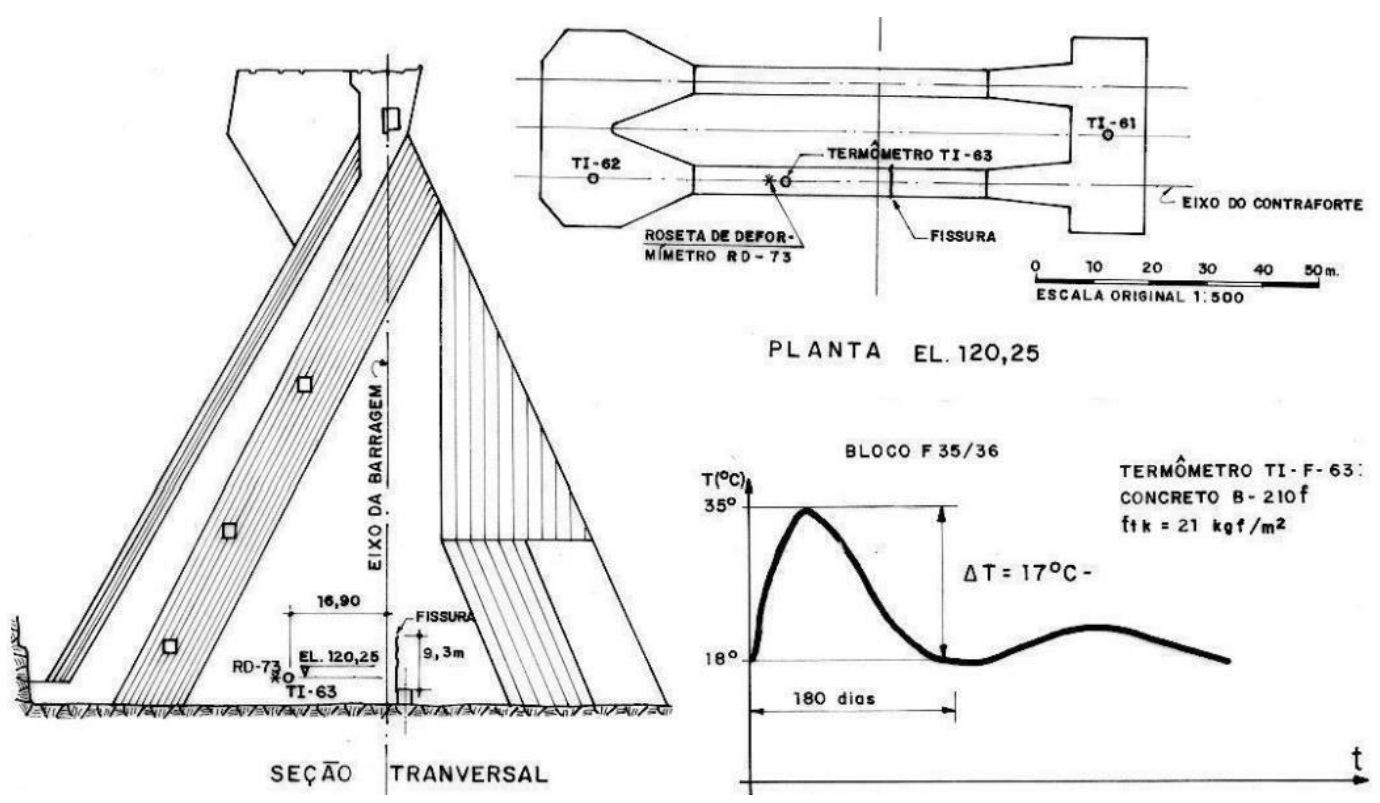

Figura 6. Fissuras na parte central de contrafortes de uma barragem.

Fonte: Silveira, Ayres e Mantese (2011).

Outro exermplo citado pelo autor é a ocorrencia de fissuras de origem térmica na cabeça da jusante de blocos na barragem de Itaipu, cujo padrão de formação da patologia é caracterizado por uma fissura mais abertas na base e se fechando gradativamente, tendo também a influência da geometria do bloco já que as fissuras ocorreram no encontro entre a mísula e a parte maciça da cabeça da jusante, conforme Figura 7.
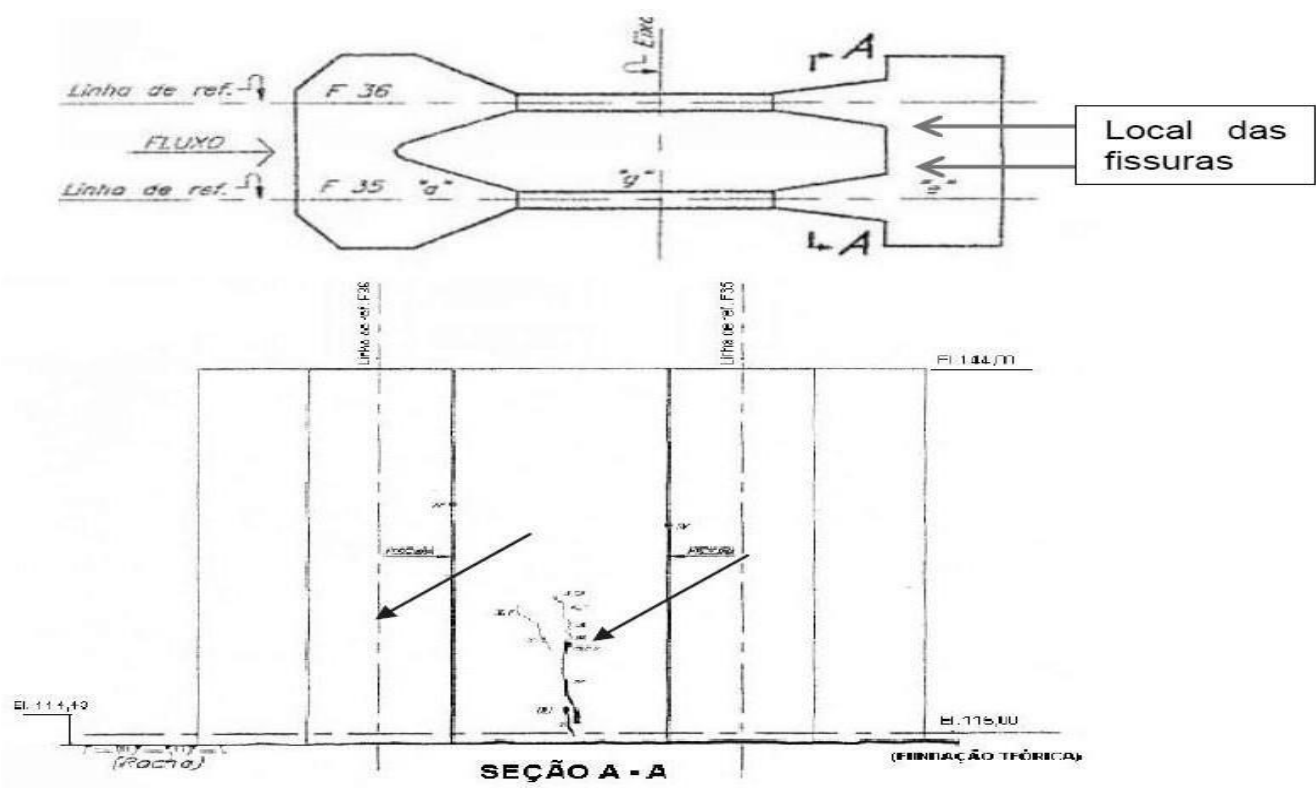

Figura 7. Fissuras de origem térmica na cabeça da jusante de um bloco nabarragem de Itaipu.

Fonte: Silveira, Ayres e Mantese (2011).

Gambale, Traboulsi e Ferreira (2015) observaram fissuras após a concretagem do tamponamento do Túnel de Desvio da UHE Batalha localizada no rio São Marcos, entre os municípios de Cristalina (GO) e Paracatu (MG) (Figura 8). Foram observadas três fissuras, sendo duas inferiores a $0,40 \mathrm{~mm}$ e outra com aproximadamente de $0,80 \mathrm{~mm}$ (Figura 9). Além disso, o autor comenta que existe a probabilidade das fissuras serem de origem térmica, devido alguns fatores tais como a temperatura de lançamento do concreto $\left(48^{\circ} \mathrm{C}\right)$, que na segunda etapa de execução foi cerca de $50 \%$ superior à prevista $\left(32{ }^{\circ} \mathrm{C}\right)$ e lançamento de camadas em intervalos diferentes, o que ocasiona elevado calor de hidratação no interior da estrutura proporcionando o surgimento de fissuras. 


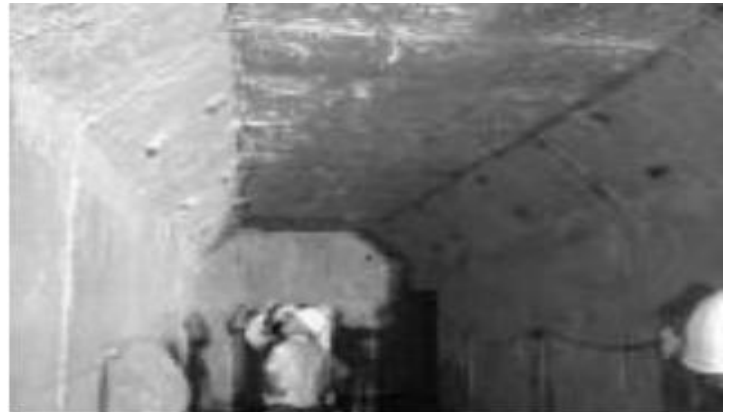

Figura 8. Tamponamento Túnel UHE Batalha.

Fonte: Gambale, Traboulsi e Ferreira (2015).

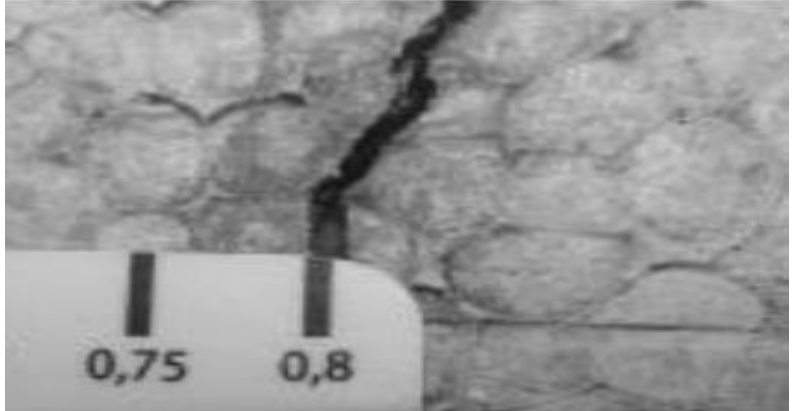

Figura 9. Fissura 0,8 mm no Túnel UHE Batalha.

Fonte: Gambale, Traboulsi e Ferreira (2015).

Essas patologias por fissuração de origem térmica não são restritas apenas a concreto de barragens, tendo ocorrências em grandes elementos de fundação, como blocos, sapatas, etc. No estudo realizado por Souza, Silva e Castro (2014) em um bloco estrutural em concreto armado, parte da fundação do edifício Trend Office Home com 31 pavimentos localizado na cidade de Goiânia foram identificadas fissuras de origém térmica. De acordo com os autores a construtora não atendeu à todos os requisitos do projeto: Utilização de cimento com baixo calor de hidratação com altos teores de adição mineral, proteção e resfriamento dos agregados, pós-resfriamento do concreto com uso de gelo, concretagem em camadas, cura úmida e proteção com lona plástica para filtrar a radiação solar. Porém, como essas especificações não foram atendidas teve-se o aparecimento de uma fissura de $3 \mathrm{~mm}$ entre as camada de concretagem, conforme a Figura 10.

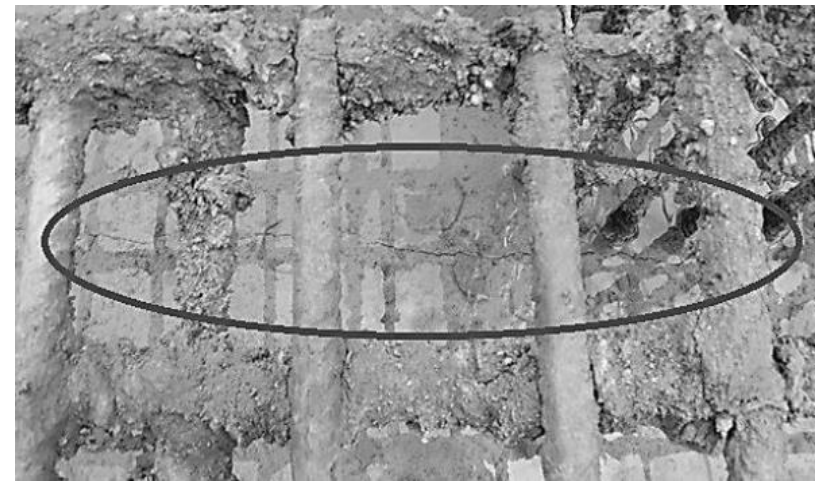

Figura 10. Fissuras de origem térmica entre camadas de concretagem de bloco estrutural.

Fonte: Souza, Silva e Castro (2014).

O mesmo autor realizou um estudo de caso em outro edifício no muninípio de Goiânia, no qual foram verificados trincas de origem térmica em sete blocos de concreto de uma fundação. Essas trincas foram ocasionadas por elevados consumo de cimentos na concretagem, sendo o consumo de cimento igual a $440 \mathrm{~kg} / \mathrm{m}^{3}$ e utilizou-se o cimento CP II F-32. Portanto, conforme afirmam os autores esse consumo de cimento é elevado e esse cimento não possui baixa geração de calor, e, contudo tem sido um gerador de calor patológico no concreto, principalmente nesses elementos de grandes dimensões. A Figura 11 apresenta essa situação em um dos blocos de concreto.

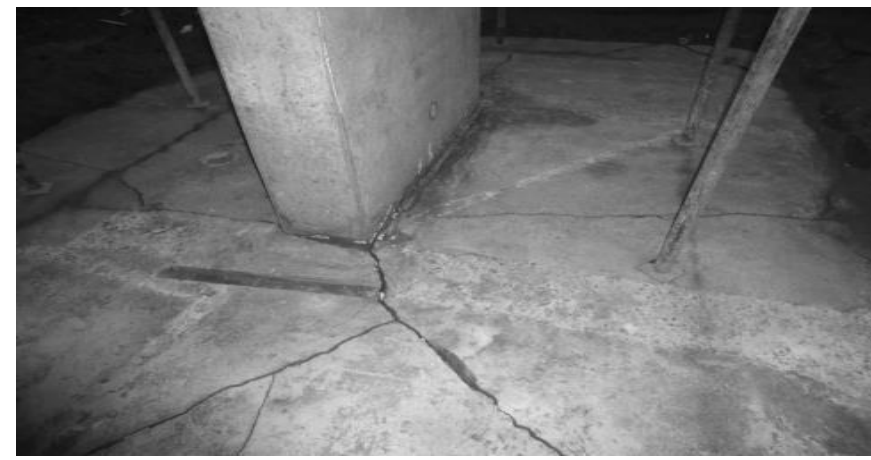

Figura 11. Fissuras de origem térmica em um dos blocos da fundação..

Fonte: Souza, Silva e Castro (2014). 
Portanto, na concretagem de elementos de grandes dimensões é necessária a utilização de cimentos com baixo calor de hidratação que possuem altos teores de adições minerais, pois os autores evidenciam que a redução do clíquer de cimento Portland reduz significativamente o calor de hidratação na execução de elementos com concreto massa, a fim de evitar problemas patológicos nessas estruturas, garantindo a durabilidade em toda a vida útil, desde que sejam realizadas as manutenções necessárias.

\section{CONCLUSÕES}

A partir da pesquisa foi possível obter um conhecimento agregado sobre o fenômeno de calor de hidratação do cimento, ressaltando a importância do controle da liberação deste calor em estruturas de concreto massa, em especial empreendimentos de barragens. Observou-se que quando ocorre a elevaçao do calor de hidratação do cimento, consequentemente verifica-se o surgimento de patologias na estrutura, a exemplo das fissuras de origem térmica. Logo, para combater esta problemática utilizam-se as adições minerais em substituição ao cimento, sendo as mais aplicadas em barragens brasileiras a sílica ativa, a cinza volante e o metacaulim. Concluiu-se ainda que as fissuração de origem térmica não são restritas apenas a concreto de barragens, tendo ocorrências em grandes elementos de fundação, tais como blocos, sapatas entre outros.

\section{REFERÊNCIAS}

AMERICAN CONCRETE INSTITUTE. ACI 207.1R-05. Guide to mass concrete. Farmington Hills. ACI, 2005.

ASSOCIAÇÃO BRASILEIRA DE NORMAS TÉCNICAS. NBR 12006. Cimento - Determinação do calor de hidratação pelo método da garrafa de Langavant. Rio de Janeiro, 1990.

ASSOCIAÇÃO BRASILEIRA DE NORMAS TÉCNICAS. NBR 12653. Materiais Pozolânicos - Requisitos. Rio de Janeiro, 2014.

ASSOCIAÇÃO BRASILEIRA DE NORMAS TÉCNICAS. NBR 12819. Concreto e argamassa - Determinação da elevação adiabática da temperatura - Método de ensaio. Rio de Janeiro, 2012.

ASSOCIAÇÃO BRASILEIRA DE NORMAS TÉCNICAS. NBR 13956-1. Sílica para uso com cimento Portland em concreto, argamassa e pasta. Parte 1: Requisitos. Rio de Janeiro, 2012.

BANDEIRA, O. M.; ANDRADE, P. D.; BITTENCOURT, R. M. O material cimentício para o projeto de Belo Monte. Revista Brasileira de Engenharia de Barragens. Comitê Brasileiro de Barragens. Edição Especial (Belo Monte). Ano IV no 04 maio de 2017.

BIANCHINI, M. Análise da influência dos teores de sílica ativa na produção de concretos de alta resistência em central dosadora de concreto. Dissertação de Pós-Graduação. Universidade Federal do Paraná. Curitiba, 2010

BICH, C. (2005). Contribuition à l'étude d la ativation thermic du kaolin: Évolution de la struture christallographique et activité pouzzolanique. Dissertação apresentada em Lyon: Institute National de Sciences Aplliquées, para obtenção do grau de Doutor, 264 .

COUTO, D.; HELENE, P.; ALMEIDA, L. C. Monitoramento de temperatura em sapata de fundação de grande porte: estudo de caso "Parque da Cidade"- SP. Revista IBRACON de Estruturas e Materiais, v. 9, n. 6, p. 953-968, 2016.

FURNAS. Concretos Massa, Estrutural, Projetado e Compactado com Rolo: Ensaios e Propriedades. Editora PINI. São Paulo, 1997.

FURNAS. Relatório DCT. C.08.046.2006-R1 - Consórcio São Salvador Civil: Estudos de Dosagens de Concreto Convencional e Caracterização dos Materiais. Goiânia, 2006. 
GAMBALE, E. A.; TRABOULSI, M. A.; FERREIRA, R. B. Avaliação termica e tensional do concreto aplicado em Estruturas de Barragens. Comitê Brasileiro de Barragens XXX Seminário Nacional de Grandes Barragens. Foz do Iguaçu, 2015.

GODKE, B. Proposta de processo de monitoramento do comportamento das fissuras térmicas em barragens de concreto de gravidade: um estudo de caso. Dissertação de Mestrado. Universidade Federal do Paraná, Curitiba, 2014

GUimarÃES, A. P. B.; NASCIMENTO, J. F. F.; BARBIN, A. S. Técnicas e Tecnologias do Concreto na UHE Santo Antônio. Revista IBRACON Concreto \& Construções, n.63, 2011.

GRAEFF, E. R. Elevação de temperatura de concretos com baixo consumo de cimento e adição de cinza volante. Dissertação de Pós-Graduação. Universidade Federal de Santa Catarina. Florianópolis, 2017.

HAN, F. et al. Characteristics of the hydration heat evolution of composite binder at different hydrating temperature. Thermochimica acta, 586, 52-57, 2014.

HASPARYK, N. P.; CAVALCANTI, A. J.C. T.; ANDRADE, W. P. Reação álcali-agregado em barragens. Revista IBRACON Concreto \& Construções, n.46, 2006.

JIANG, G.; RONG, Z.; SUN, W. Effects of metakaolin on mechanical properties, pore structure and hydration heat of mortars at $\mathbf{0 . 1 7}$ w/b ratio. Construction and Building Materials, n.93 564-572, 2015.

JÚNIOR, E. I. F. Influência do tipo de cimento Portland no desempenho de pastas e argamassas a partir de medidas calorimétricas: uma contribuição ao estudo de desempenho do concreto. Dissertação de Mestrado. Instituto de Pesquisas Tecnológicas do Estado de São Paulo - IPT. São Paulo, 2018.

KIM, S. J.; YANG, K. H.; MOON, G. D. Hydration characteristics of low-heat cement substituted by fly ash and limestone powder. Materials, v. 8, n. 9, p. 5847-5861, 2015.

KWAN, A. K. H. et al. Effects of Silica Fume on Heat Generation of Curing Concrete. ACI Materials Journal, v.108, n.6, 2011.

LANGAN, B. W.; WENG, K.; WARD, M. A. Effect of silica fume and fly ash on heat of hydration of Portland cement. Cement and concrete research, v. 32, n. 7, p. 1045-1051, 2002.

LIMA, D. V. F.; NOGUEIRA, A. A. Tecnologias Utilizadas na execução de obras das eclusas de Tucuruí. $58^{\circ}$ Congresso Brasileiro do Concreto (IBRACON), 2016.

MATOS, P. R.; JUNCKES, R.; PRUDÊNCIO JR, L. R. Influência do uso de cinza volante na elevação adiabática de temperatura e resistência à compressão de concretos. Revista Matéria, v.24, n.2, 2019.

MEDINA, E. A. Pozolanicidade do metacaulim em sistemas binários com cimento Portland e hidróxido de cálcio. Dissertação de Mestrado. Universidade de São Paulo, 2011.

MEHTA, P. K.; MONTEIRO, P. J. M. Concreto. Microestrutura, propriedades e materiais. 3. ed. São Paulo: IBRACON, 2008.

MELO, S. K. Estudo da formação da etringita tardia em concreto por calor de hidratação do cimento. Dissertação de Pós-graduação. Universidade Federal do Goiás. Goiânia, 2010.

MOON, H. et al. Revisiting the effect of slag in reducing heat of hydration in concrete in comparison to other supplementary cementitious materials. Materials, v. 11, n. 10, p. 1847, 2018.

NEVILlE, A. M. Propriedades do concreto. 5. ed. Porto Alegre: Bookman, 2016. 
PEDROSO, F. L. Grandes Barragens Brasileiras e suas histórias. Revista IBRACON Concreto \& Construções, n.63, 2011.

RIBEIRO, A. V. S. Influência de adições minerais na elevação da temperatura de concretos massa de elevada resistência a compressão. Dissertação de Mestrado. Universidade Federal de Santa Catarina. Florianópolis, 2018.

RONG, Z. D. et al. Effect of silica fume and fly ash on hydration and microstructure evolution of cement based composites at low water-binder ratios. Construction and Building Materials, v. 51, p. 446-450, 2014.

SANTOS, S. B. Análise da fluência do concreto massa nas primeiras idades de carregamento: influência de aditivos plastificantes e adições minerais. Tese de Doutorado. Universidade Federal do Rio Grande do Sul. Porto Alegre, 2011.

SINGH, N. B. et al. Hydration of ternary cementitious system: Portland cement, fly ash and silica fume. Journal of Thermal Analysis and Calorimetry, v. 119, n. 1, p. 381-389, 2015.

SILVA, K. D. C. Avaliação da Atividade Pozolânica dos Resíduos de Lã de Rocha, Fibra de Vidro e Lã de Vidro. Dissertação de Mestrado. Universidade Federal de Ouro Preto. Ouro Preto, 2016.

SILVEIRA, J. F. A.; AYRES, M. C.; MANTESE, A. C. Fissuras em Barragens de Concreto - Critérios de classificação, experiência prática e tratamentos. IBRACON, 2018.

SOUZA, A. L.; SILVA, I. R. R.; CASTRO, P. R. M. Retração térmica e Fissuração em concreto por calor de hidratação. Trabalho de Conclusão de Curso. Universidade Federal do Goiás. Goiânia, 2014.

SOUZA, G. T. Dosagem experimental de concreto massa com adição de sílica ativa aplicado em barragem. Dissertação de Mestrado. Universidade Federal do Pará, 2017.

SOUZA, P. S. L. Verificação da Influência de Metacaulim de alta reatividade nas propriedades mecânicas do concreto de alta resistência. Tese de Doutorado. Universidade Federal do Rio Grande do Sul. Porto Alegre, 2003.

TAYLOR, H. F. W. Cement chemistry. London: Thomas Telford; 1997.

WANG, J. C.; YAN, P. Y. Influence of initial casting temperature and dosage of fly ash on hydration heat evolution of concrete under adiabatic condition. Journal of thermal analysis and calorimetry, v. 85, n. 3, p. 755-760, 2006.

ZANOTTI, J. A. C. Usina hidrelétrica Jirau. Revista IBRACON Concreto \& Construções, n.63, 2011.

ZORZI, R. R.; RIGOTI, A. Aplicação de métodos geoelétricos para monitoramento da barragem de concreto da UHE Gov. José Richa. Boletim Paranaense de Geociências, vol. 64-65, 48-58, 2011. 